\title{
RESEARCH ON PAIN SCORES FOR DIFFERENT ARTERIAL PUNCTURE SITES FOR BLOOD GAS ANALYSIS
}

\author{
Burak Katipoglu' ${ }^{1}$, Togay Evrin ${ }^{1}$ \\ ${ }^{1}$ Ufuk University Dr Ridvan Ege Research And Training Hospital, Ankara, Turkey
}

\begin{abstract}
INTRODUCTION: In emergency departments, it is important to have tests that give fast results especially in the diagnosis and treatment of critically ill patients. Blood gas analysis has an important role in the diagnosis and treatment of patients applying for emergency services. On the other hand, taking samples for blood gas may differ based on clinic properties of patients. Puncture of arteries in sampling is a painful procedure. It is aimed to evaluate the differences between visual analogue pain scales of patients based on different punctured veins.

METHODS: In this retrospective study, files of patients attempted to Ufuk University, Medical Faculty Dr Ridvan Ege Education and Research Hospital, Department of Emergency Medicine between 01.01.201531.12.2017 with the punctured veins process at the age of 18-65 were examined.

RESULTS: A total of 84 patient files, including 55 radial and 31 femoral punctured veins, were subjected to the research. $36.4 \%$ of patients in the radial group were female, and $63.6 \%$ of them were male. In the femoral group, $45.2 \%$ of patients were female and $54.8 \%$ were male. Gender differences between groups were found to be statistically insignificant $(p>0.05)$. BMI of groups was also statistically insignificant $(p>0.05)$. Chronic disease distribution was found to be statistically insignificant between the groups $(p>0.05)$. VA score of the femoral group $(6.32 \pm 1.70)$ was significantly higher than the radial group $(5.15 \pm 1.98)$ $(p<0.05)$. In the sampling difficulty groups, patients whose samplings were difficult were significantly higher than other groups $(p<0.05)$.
\end{abstract}

CONCLUSIONS: In conclusion, VA score for femoral arterial puncture is higher than a radial arterial puncture. In other words, taking blood gas with the radial arterial procedure is less painful than the femoral arterial procedure. In addition, hypertension is also an important factor affecting pain after arterial puncture with VAS.

KEY WORDS: arterial puncture, blood gas analysis, pain score

Disaster Emerg Med J 2019; 4(1): 5-8

\section{INTRODUCTION}

Arterial puncture for blood gas analysis is especially common in emergency departments [1]. Analysis of arterial blood gas is a gold standard for evaluation of acid-base equation of metabolism and respiration patients [2]. It is known as a painful procedure for many patients, and some physical relief methods such as ice bags are applied to reduce this pain [3]. In clinical applications, the generally used arteries are radial, brachial and femoral arteries.

Radial arterial puncture is one of the most common procedures for blood gas analysis [4]. Another method for puncturing blood gas analysis is a femoral artery puncture $[5,6]$. It is also known as a Common Femoral Artery puncture - CFA puncture [7]. In both femoral and radial artery punctures the malpractice issues have been reported [8-14]. 
Patients suffering from chronic diseases led to hypoxemia and dyspnea such as COPD, pulmonary emboli, or heart failures are frequently subjected to arterial puncture. These patients are more frequently faced with the risk of complications. Pain experienced by a patient may be indicative of complication or patient's safety. In order to apply the correct methods effectively and accordingly with patient safety guidelines, less painful methods have become of vital importance. It was aimed to evaluate the differences between a visual analogue pain scales of patients based on different punctured veins.

\section{MATERIALS AND METHODS}

In this retrospective study, files of patients admitted to Ufuk University, Medical Faculty Dr Ridvan Ege Education and Research Hospital, Department of Emergency Medicine between 01.01.201531.12.2017 with the punctured artery process at the age between 18-65 were examined. A Total of 84 patient files, including 55 radial and 31 femoral punctured ateries, were subjected to the research.

In the statistical analysis, SPSS 17. for windows was used. Binary and nominal parameters were described with frequency analysis, whereas mean and standard deviations were used to describe scaled parameters. Chi-Square analysis and likelihood ratio were used for differences between categorical parameters. Before difference analysis of scale parameters, the Kolmogorov Smirnov test was used for normality of parameters. Since distributions were found to be non normal, Mann Whitney-U test was used for differences between two groups, and the Kruskal Wallis test was used for differences between more than two groups. Binary Logistic Regression analysis was used for multifactorial regression of binary parameters. All analyses were performed at $95 \% \mathrm{Cl}$ with a 0.05 alpha significance level.

\section{RESULTS}

Baseline characteristics of patient groups were given in Table 1.

$36.4 \%$ of patients in the radial group were female, and $63.6 \%$ of were male. In the femoral group, $45.2 \%$ of were female and $54.8 \%$ were male. Gender differences between groups were found to be statistically insignificant $(p>0.05)$. BMI of groupswas also statistically insignificant $(p>0.05)$. Chronic and other disease rates of patient groups were given in Table 2 .

Patients suffering of CHD, CKF, hypoxemia and apnea were higher in the radial group, whereas $\mathrm{DM}$, hypertension, CHF, COPD and malignancy were higher in the femoral group. Chronic disease distribution was found to be statistically insignificant between the groups $(p>0.05)$. VAS differences of patient and difficulty groups were presented in Table 3.

VA score of the femoral group $(6.32 \pm 1.70)$ was significantly higher than in the radial group $(5.15 \pm 1.98)(p<0.05)$. In sampling difficulty

Table 1. Baseline characteristics of patient groups
\begin{tabular}{|c|l|l|c|}
\hline & Radial $(n=55)$ & Femoral $(n=31)$ & $p$ \\
\hline Gender & & & $0.423^{\mathrm{a}}$ \\
\cline { 1 - 2 } Female & $20(36.4)$ & $14(45.2)$ & \\
\cline { 1 - 2 } Male & $35(63.6)$ & $17(54.8)$ & \\
\cline { 1 - 2 } BMl & & & \multirow{2}{*}{$0.050^{\mathrm{a}}$} \\
\cline { 1 - 2 } 25 & $22(40.0)$ & $6(19.4)$ & \\
\hline$>25$ & $33(60.0)$ & $25(80.6)$ & \\
\hline
\end{tabular}

a. Chi-Square Test, b. Likelihood Ratio Test

Table 2. Chronic and other disease rates of patient groups
\begin{tabular}{|l|l|l|l|}
\hline & \multicolumn{1}{|c|}{ Radial $(\mathrm{n}=55)$} & \multicolumn{1}{|c|}{ Femoral $(\mathrm{n}=31)$} & \multicolumn{1}{c|}{$\mathrm{p}$} \\
\hline Diabetes Mellitus (DM) & $19(34.5)$ & $12(38.7)$ & $0.699^{\mathrm{a}}$ \\
\hline Hypertension (HT) & $28(50.9)$ & $21(67.7)$ & $0.130^{\mathrm{a}}$ \\
\hline Chronic Heart Disease (CHD) & $17(30.9)$ & $7(22.6)$ & $0.408^{\mathrm{a}}$ \\
\hline Chronic Heart Failure (CHF) & $13(23.6)$ & $10(32.3)$ & $0.386^{\mathrm{a}}$ \\
\hline Chronic Kidney Failure (CKF) & $9(16.4)$ & $3(9.7)$ & $0.379^{\mathrm{b}}$ \\
\hline Chronic Obstructive Pulmonary Disease (COPD) & $22(40.0)$ & $15(48.4)$ & $0.451^{\mathrm{a}}$ \\
\hline Malignancy & $3(5.5)$ & $3(9.7)$ & $0.469^{\mathrm{b}}$ \\
\hline Hypoxemia & $25(45.5)$ & $13(41.9)$ & $0.752^{\mathrm{a}}$ \\
\hline
\end{tabular}


groups, patients whose sampling was difficult were significantly higher than other groups $(p<0.05)$. In order to analyze the isolated effects of VAS of patients based on different punctured veins, binary logistic regression analysis was performed, and results were given in Table 4.

According to the binary logistic regression analysis, HT (OR: 0.240; $p<0.05)$ and VA scores (OR: $1.559 ; p<0.05)$ have statistically significant effects on different punctured veins.

\section{DISCUSSION}

Blood gas analysis is a common and a gold standard procedure for metabolic and respiratory-related health problems [1]. Radial, femoral and brachial arteries are the arteries most often used for blood gas analysis. During the arterial puncture process, complication risks and pain which drives down the quality of life of patients are especially faced by respiratory and COPD patients, who receive

\begin{tabular}{|c|c|c|c|}
\hline & $f$ & VAS & $\mathrm{p}$ \\
\hline \multicolumn{3}{|l|}{ Group } & \multirow[t]{3}{*}{$0.003_{a}$} \\
\hline Radial & 55 & $5.15 \pm 1.98$ & \\
\hline Femoral & 31 & $6.32 \pm 1.70$ & \\
\hline \multicolumn{3}{|l|}{ Sample taking difficulty } & \multirow[t]{4}{*}{$0.002_{b}$} \\
\hline Easy & 46 & $4.93 \pm 1.70$ & \\
\hline Mild & 25 & $5.84 \pm 1.75$ & \\
\hline Difficult & 15 & $7.07 \pm 2.22$ & \\
\hline
\end{tabular}

a - Mann Whitney-U Test, b - Kruskal Wallis Test blood gas procedure more frequently $[15,16]$. The pain may be interpreted as a reaction of the body, and pain levels of patients are also part of this reaction. In literature, there has not been a consensus on a selection of arterial puncture artery in general procedure. Thus, it is important to compare arterial puncture procedures in terms of pains experienced by patients.

In literature, there have been researches arguing that gender and BMI level of patients affect the pain they perceive [15-19]. In our study, gender and BMI distribution of patient groups were not significantly different. Thus, it may be argued that the effects of gender and BMI had been eliminated by the gender distribution of our sample.

Chronic diseases have their own characteristics and pain patterns. In our study, CHD, CKF, hypoxemia and apnea were higher in the radial group. On the other hand, DM, hypertension, CHF, COPD and malignancy were higher in the femoral group. However, chronic diseases of patients in our sample were not significantly different. For this reason, it may be argued that possible effects of chronic diseases on the pain of the arterial puncture did not affect the results of the study. In other words, the reliability of results of the study in terms of chronic diseases is higher.

According to our results, VA score was significantly higher in the femoral group patients. As expected, patients whose sampling processes were difficult had higher VA scores. In binary logistic regression, VAS and HT were found to be effective factors for the groups. In other words, either femoral or radial arterial puncture has a statistically significant

Table 4. Binary Logistic Regression results

\begin{tabular}{|l|l|l|l|l|l|l|} 
& \multicolumn{1}{|c|}{ B } & \multicolumn{1}{c|}{ S.E. } & \multicolumn{1}{c|}{ Wald } & \multicolumn{1}{c|}{ Sf } & \multicolumn{1}{c|}{ OR } \\
\hline BMI(1) & $-0,714$ & 0,805 & 0,787 & 1 & 0,375 & 0,490 \\
\hline DM(1) & 0,151 & 0,702 & 0,046 & 1 & 0,829 & 1,163 \\
\hline HT(1) & $-1,428$ & 0,663 & 4,632 & 1 & 0,031 & 0,240 \\
\hline CHD(1) & 0,217 & 0,698 & 0,096 & 1 & 0,756 & 1,242 \\
\hline CHF(1) & $-0,104$ & 0,729 & 0,020 & 1 & 0,886 & 0,901 \\
\hline CKF(1) & 1,204 &, 897 & 1,800 & 1 & 0,180 & 3,332 \\
\hline COPD(1) & 0,366 & 0,654 & 0,313 & 1 & 0,576 & 1,441 \\
\hline Malignancy (1) & $-2,413$ & 1,272 & 3,602 & 1 & 0,058 & 0,090 \\
\hline Hypoxemia(1) & 0,099 & 0,719 & 0,019 & 1 & 0,890 & 1,105 \\
\hline Apnea(1) & 0,494 & 0,737 & 0,449 & 1 & 0,503 & 1,639 \\
\hline VAS & 0,444 & 0,216 & 4,217 & 1 & 0,040 & 1,559 \\
\hline Constant & $-4,223$ & 2,297 & 3,379 & 1 & 0,066 & 0,015 \\
\hline
\end{tabular}


effect on the pain patients experienced, and HT is also a risk factor affecting pain for arterial blood gas sampling procedure. Thus, it may be recommended to select the femoral arterial puncture especially for patients with $\mathrm{HT}$ in order to minimize their pain for arterial puncture process.

\section{CONCLUSIONS}

Results of the study showed that the VA score for the femoral arterial puncture is higher than the radial arterial puncture. In other words, sampling blood gas with the radial arterial procedure is less painful than the femoral arterial procedure. In addition, hypertension is also an important factor affecting pain after arterial puncture with VAS.

Conflicts of Interest: The authors declare that there is no conflict of interest regarding the publication of this paper.

Funding Statement: The research was funded by the authors' own budget.

\section{REFERENCES}

1. Laursen $C B$, Pedersen $R$, Lassen $A$. Ultrasound guided puncture of the radial artery for blood gas analysis: a prospective, randomized controlled trial. Scandinavian Journal of Trauma, Resuscitation and Emergency Medicine. 2015; 23(S1), doi: 10.1186/1757-7241-23-s1-a16.

2. Larkin BG, Zimmanck RJ. Interpreting Arterial Blood Gases Successfully. AORN J. 2015; 102(4): 343-357, doi: 10.1016/j.aorn.2015.08.002, indexed in Pubmed: 26411819.

3. Haynes JM. Randomized Controlled Trial of Cryoanalgesia (Ice Bag) to Reduce Pain Associated With Arterial Puncture. Respiratory Care. 2014; 60(1): 1-5, doi: 10.4187/respcare.03312.

4. Dev SP, Hillmer MD, Ferri M. Arterial Puncture for Blood Gas Analysis. N Engl J Med. 2011; 3: 364-367, doi: 10.1056/NEJMvcm0803851.

5. Adlan $T$, Shahin $Y$, Kember $P$, et al. Retrospective cohort study on Angio-Seal closure device safety and effectiveness in antegrade superficial femoral artery punctures: A comparison with antegrade common femoral artery punctures. Int J Surg. 2017; 48: 225-227, doi: 10.1016/j.ijsu.2017.11.003, indexed in Pubmed: 29146270.

6. Ruzsa Z, Bellavics R, Nemes B, et al. Combined Transradial and Transpedal Approach for Femoral Artery Interventions. JACC Cardiovasc Interv. 2018; 11(11): 1062-1071, doi: 10.1016/j.jcin.2018.03.038, indexed in Pubmed: 29880100.
7. Berg VD. Optimal Technique for Common Femoral Artery Access. Endovascular Today. 2013; 1: 58-61.

8. Hwang J, Park S, Kim K, et al. Ultrasonography-guided antegrade common femoral artery puncture: factors associated with puncture time. Journal of Vascular and Interventional Radiology. 2018; 29(4): 277-278.

9. Gaudino M, Burzotta F, Bakaeen F, et al. Arterial Grafting International Consortium Alliance. The Radial Artery for Percutaneous Coronary Procedures or Surgery? J Am Coll Cardiol. 2018; 71(10): 1167-1175, doi: 10.1016/j.jacc.2018.01.013, indexed in Pubmed: 29519357.

10. Zaryanova GT, Díaz AA, Bermejillo CB, et al. Complete femoral artery transection following handlebar trauma. Trauma Case Reports. 2017; 9: 1-4, doi: 10.1016/j.tcr.2017.01.003.

11. Ünal $S, A c ̧ a r ~ B$, Yayla Ç, et al. Manual heating of the radial artery (Balbay manoeuvre) to facilitate radial puncture prior to transradial coronary catheterization. Rev Port Cardiol. 2017; 36(6): 409-414, doi: 10.1016/j.repc.2016.11.008, indexed in Pubmed: 28552240.

12. Kweon M, Bhamidipaty V, Holden $A$, et al. Antegrade superficial femoral artery versus common femoral artery punctures for infrainguinal occlusive disease. J Vasc Interv Radiol. 2012; 23(9): 1160-1164, doi: 10.1016/j.jvir.2012.06.006, indexed in Pubmed: 22832141.

13. Gabriel M, Pawlaczyk K, Waliszewski K, et al. Location of femoral artery puncture site and the risk of postcatheterization pseudoaneurysm formation. Int J Cardiol. 2007; 120(2): 167-171, doi: 10.1016/j. ijcard.2006.09.018, indexed in Pubmed: 17250906.

14. Spies JB, Berlin L. Complications of femoral artery puncture. AJR Am J Roentgenol. 1998; 170(1): 9-11, doi: 10.2214/ajr.170.1.9423587, indexed in Pubmed: 9423587.

15. Hernández-Padilla JM, Granero-Molina J, Márquez-Hernández VV, et al. Development and psychometric evaluation of the arterial puncture self-efficacy scale. Nurse Educ Today. 2016; 40: 45-51, doi: 10.1016/j. nedt.2016.02.008, indexed in Pubmed: 27125149.

16. Fairley SL, Lucking AJ, McEntegart M, et al. Routine Use of Fluoroscopic-Guided Femoral Arterial Puncture to Minimise Vascular Complication Rates in CTO Intervention: Multi-centre UK Experience. Heart Lung Circ. 2016; 25(12): 1203-1209, doi: 10.1016/j.hlc.2016.04.006, indexed in Pubmed: 27265645.

17. Higgins D, Buta E, Heapy A, et al. (208) The relationship among BMI, pain intensity, and musculoskeletal diagnoses. The Journal of Pain. 2016; 17(4): S28, doi: 10.1016/j.jpain.2016.01.112.

18. Okifuji $A$, Hare $B D$. The association between chronic pain and obesity. J Pain Res. 2015; 8: 399-408, doi: 10.2147/JPR.S55598, indexed in Pubmed: 26203274.

19. Seaman DR. Body mass index and musculoskeletal pain: is there a connection? Chiropr Man Therap. 2013; 21(1): 15, doi: 10.1186/2045709X-21-15, indexed in Pubmed: 23687943. 